\title{
LA CLÁUSULA DE MEDIACIÓN EN EL ÁMBITO DE LA CONTRATACIÓN
} CIVIL Y MERCANTIL

JUANA MARÍA PARDO LOZANO

jmpardo@universitaslegis.com

Universidad de Almería (UAL)

\section{RESUMEN}

En la presente se analiza la conveniencia de incluir en los contratos civiles y mercantiles un pacto de sometimiento a la mediación de los conflictos que pudieren derivarse de los mismos. Se estudian las ventajas e inconvenientes de incluir cláusulas de mediación en los citados contratos en contraposición a las cláusulas de sometimiento a los procedimientos judiciales o arbitrales. Se hace especial referencia al principio de autonomía de la voluntad de las partes que rige los contratos y al principio de voluntariedad que aplica a la mediación.

\section{Palabras clave:}

Mediación, resolución extrajudicial de conflictos, cláusula de mediación, contrato, jurisdicción.

\section{ABSTRACT}

In case of conflicts derived from civil or commercial contracts, the convenience of including clauses related to mediation in order to solve the referred conflicts is here analyzed. The advantages and disadvantages of including mediation clauses are studied with regards to the clauses in which it is established that the conflicts will be submitted to Tribunals or Arbitrators. There is a special reference to the principle of party autonomy applied to contracts and to the voluntary mediation.

\section{Keywords:}

Mediation, alternative dispute resolution, clause of submission to mediation, contract, jurisdiction. 


\section{Introducción.}

Uno de los retos del Estado de Derecho es garantizar la tutela judicial efectiva mediante la implantación de un sistema de calidad que permita resolver los diversos conflictos que se derivan de las relaciones sociales. En la práctica, en nuestro país el sistema más habitual de resolución de las controversias es el jurisdiccional, de forma que los juzgados y tribunales tras la sustanciación del procedimiento judicial dictan la correspondiente sentencia. Sin embargo, se ha detectado que ello no siempre es una solución eficiente, ya que en muchas ocasiones la respuesta se obtiene muy tarde y no hay siempre voluntad de cumplir la sentencia por parte de la condenada.

Es por ello que en el presente se aborda un sistema de resolución de conflictos alternativo que podría incluso pactarse con carácter previo a que surja el conflicto. En particular, se analiza la posibilidad de prever como sistema alternativo, la mediación que se establecería con ocasión de la suscripción del correspondiente contrato civil o mercantil. Se trata de un procedimiento en el que de forma voluntaria intervienen las partes junto con un profesional neutral quien ayuda a resolver el conflicto por las propias partes.

Se hace también referencia a su aplicabilidad en otros países comunitarios y en especial a USA en donde la mediación sirve de referente para España al contar dichos países con una larga trayectoria. En el ámbito comunitario, cabe destacar las dificultades que se están presentando respecto de la convergencia de las normativas europeas en materia de mediación debido a la diferente acogida social que esta institución tiene en los distintos ordenamientos jurídicos europeos, así como la escasa regulación que se desprende de la Directiva. La norma comunitaria es una norma de mínimos en la que no se estipulan de forma exhaustiva cuestiones tales como sus principios informadores, el estatuto del mediador, los requisitos de formación exigibles o su procedimiento. En consecuencia, el proceso de transposición está siendo muy heterogéneo. No obstante lo anterior, hay un 
principio que sí recoge la Directiva, el de voluntariedad, al indicar que la mediación debe ser un proceso voluntario.

Asimismo, se analizan las implicaciones que se derivarían en caso de que una de las partes renunciara al sometimiento a la mediación, una vez pactada la misma por escrito, teniendo en cuenta el carácter voluntario de dicha institución. Podría ocurrir que habiéndose pactado someterse a la mediación en caso de controversia, una de las partes le comunicara a la otra su deseo de iniciar un proceso de mediación y la contraparte se negara. En este supuesto cabe plantearse cómo afecta a los plazos de caducidad y prescripción de presentación de la demanda ante los tribunales de justicia. Por otro lado, se estudia el supuesto en el que una de las partes contratantes, sin cumplir lo pactado en el contrato en cuanto al sometimiento de la controversia a la mediación, acudiera directamente a los juzgados o en su caso, a la Corte de Arbitraje.

\section{La mediación como “Alternative Dispute Resolution” (“ADR”).}

La mediación es un método de resolución de conflictos alternativa (también llamada “ADR" o "Alternative Dispute Resolution”) que se está fomentando desde las instituciones públicas, tanto europeas y nacionales, como autonómicas. Ello responde a varias causas, principalmente a la sobrecarga de trabajo de los tribunales y al entenderse que los mismos no siempre dan una solución satisfactoria para las partes, sin olvidar además la ruptura de la relación contractual que tuvieran las partes. Ello conlleva además que las sentencias judiciales sean incumplidas en numerosas ocasiones y en otras, recurridas ante los órganos jurisdiccionales de superior jerarquía.

La Directiva 2008/52/CE sobre ciertos aspectos de la mediación en asuntos civiles y mercantiles publicada en el DOUE en mayo de 2008 no fue transpuesta en el ordenamiento español hasta 2012. La transposición se realizó mediante la aprobación y publicación de la Ley de mediación en asuntos civiles y mercantiles aprobada mediante Real-Decreto Ley 5/2012, de 5 de marzo $^{1}$ (en lo sucesivo, “ $L M$ ”). Posteriormente, se

\footnotetext{
${ }^{1}$ Publicada en BOE el 7 de julio de 2012.
} 
aprobó el Real Decreto 980/2013, de 13 de diciembre ${ }^{2}$, mediante el que se desarrolla la referida ley y en particular: la formación de los mediadores; la publicidad de los mismos y de las instituciones de mediación; el alcance de la obligación de aseguramiento de la responsabilidad civil de dichos mediadores y el procedimiento de mediación por medios electrónicos.

Se trata de las primeras normas que se aprueban en nuestro país para regular de forma sistemática la mediación civil y mercantil. Esta materia ha sido regulada antes en países anglosajones con mayor tradición a la hora de someterse a procesos de mediación. En Europa el proceso ha sido desigual, ya que la referida Directiva recoge directrices generales y hace referencia a su aplicación en conflictos transfronterizos.

El legislador español fue más allá de la regulación genérica que reconocía la Directiva, instituyendo como pilares de la mediación en nuestro sistema español, el principio de voluntariedad, la deslegalización del proceso $^{3}$ y el carácter ejecutivo del título en el que se recogiera el acuerdo. El acuerdo alcanzado puede elevarse a público ante fedatario público u homologarse judicialmente, por lo que dichos títulos serán de obligado cumplimiento y tendrán fuerza ejecutiva.

Cabe señalar que cada vez es más habitual que en nuestro país los empresarios acudan al arbitraje como forma alternativa a la judicial para la resolución de los conflictos derivados de sus relaciones comerciales, así como a la mediación, si bien en este ámbito queda todavía mucho camino por andar. El mediador es un tercero neutral, debidamente formado para ello, designado por las partes que trata de ayudar a que las mismas solventen la disputa alcanzando un acuerdo satisfactorio para ambas.

Este medio de resolución de conflictos en el que las partes tratan de alcanzar un acuerdo “win win” con la colaboración de un tercero, está ganando adeptos y popularidad entre

\footnotetext{
2 Publicado en BOE el 27 de diciembre de 2013.

3 En el sentido de perder protagonismo la ley en favor del principio de autonomía de la voluntad de las partes. Asimismo cabe añadir el principio de la flexibilidad del contenido del acuerdo resultante de la mediación.
} 
empresarios y abogados continentales ${ }^{4}$. A ello contribuye el ahorro de tiempo, coste y posibilidad de continuar con una relación contractual en términos amistosos. A pesar de las ventajas que presenta, no está muy extendido en nuestro país, sin embargo sí lo está en países anglosajones. Su uso en países como Francia o Italia está siendo cada vez más habitual.

\subsection{El proceso de mediación. Ventajas e inconvenientes.}

La mediación se considera un instrumento eficaz complementario al de la Administración de Justicia para la resolución de controversias cuando el conflicto jurídico afecta a derechos subjetivos de carácter disponible ${ }^{5}$. El procedimiento de mediación dista sustancialmente del proceso en sede judicial, por lo que en lugar de tomar como referentes obligados sus principios más garantistas, debe aproximarse a la lógica de la negociación.

Puede sostenerse que nuestro sistema español vigente se basa en un modelo de mediación facilitativa en el que el mediador orienta a las partes y trata de acercar sus posturas e intereses para facilitar que lleguen a un acuerdo, en contraposición a la mediación evaluativa, en la que el mediador toma posición en el conflicto y formula una propuesta de resolución que se equilibrada para las partes ${ }^{6}$.

Se encuentran, entre otras, las siguientes ventajas de la mediación:

- Ahorro de costes.

\footnotetext{
${ }^{4}$ CLIFFORD J. H., "La mediación empresarial: una inversión indiscutible”, La Ley, 2013, p. 1.

${ }^{5}$ No obstante, pese al auge experimentado en los últimos años en nuestro país, no deja de existir un número considerable de operadores jurídicos y económicos que contempla con cierto escepticismo y recelo este medio alternativo de resolución de conflictos. En este sentido HUALDE MANSA, Teresa, "La Mediación en asuntos civiles y mercantiles. La transposición de la Directiva 2008/52 en Francia y en España”, La Ley, Madrid, p. 159.

${ }^{6}$ El Anteproyecto de Ley de Mediación recogía, según expone el Informe a dicho Anteproyecto elaborado por el Consejo General del Poder Judicial (CGPJ), un modelo de mediación "evaluativa." En Italia se recoge también este modelo ya que se faculta expresamente al mediador para proponer un acuerdo (Decreto Legislativo de 4 de Marzo de 2010, núm. 28 y Decreto Ley de 21 de junio de 2013, núm. 69 -convertido en ley el 9 agosto de 2013, núm. 98-).
} 
- Ahorro de tiempo.

- Control del proceso.

- Mantenimiento de la relación contractual.

Por su parte, debemos reconocer que entraña ciertos riesgos caso de no alcanzarse un acuerdo y tener que acudir a los tribunales:

- Asunción de los costes de la mediación.

- Retraso en la interposición de las acciones judiciales o arbitrales.

- Riesgo de que la otra parte tenga conocimiento de determinada información que pueda perjudicarle o el propio mediador, como tercero, si bien éste está sometido a su deber de confidencialidad.

No obstante, entendemos que a pesar de los riesgos referidos y teniendo en cuenta las ventajas que presenta, así como los índices de éxito que arrojan las estadísticas, la mediación es un proceso de resolución de conflictos al que merece la pena acudir. Para ello, las Administraciones públicas tendrán que seguir divulgando esta institución y formando a los operadores jurídicos ${ }^{7}$.

Conviene mencionar, a modo ilustrativo, los datos estadísticos de la Cámara de Comercio Internacional (CCI), así como el Centro de Mediación y Arbitraje de París (CMAP) que arrojan tasas de éxito cercanas al 70\%. Por su parte, en USA los supuestos en los que se alcanzaría un acuerdo en procesos de mediación rondarían el 80\%. Dichas cifras se aproximan a las tasas de éxito en nuestro país cuando las partes deciden someter sus controversias a un proceso de mediación extrajudicial.

\footnotetext{
${ }^{7}$ Se considera esencial que la sociedad en general, ciudadanos y empresarios, conozcan este sistema alternativo de resolución de conflictos, así como los propios letrados que tienen siempre la posibilidad de hacerlo con carácter previo si las partes están de acuerdo. A este respecto deben recordarse las palabras de Abrahan Lincoln: "Discourage litigation. Persuade your neighbors to compromise whenever you can. Point out to them how the nominal winner is often a real loser -in fees, expenses and waste of time. As a peacemaker the lawyer has a superior opportunity of being a good man. There will still be business enough." O traducido al español: "Evita el litigio. Trata de convencer a tus vecinos de llegar a un acuerdo siempre que sea posible. Hazles ver cómo el ganador es a menudo el perdedor -en honorarios, gastos y tiempo. Como mediador el abogado tiene una oportunidad única de ser una buena persona. Quedará negocio suficiente".
} 


\subsection{Mediación extrajudicial e intrajudicial.}

Se entiende como mediación extrajudicial el supuesto en el que las partes se someten a un procedimiento de mediación para resolver un conflicto que no está judicializado. En caso de alcanzarse un acuerdo, éste podrá ser elevado a público ante fedatario público y tendrá fuerza ejecutiva ante los Tribunales. En contraposición, estaríamos ante una mediación intrajudicial cuando las partes enfrentadas que han iniciado un proceso judicial son dirigidas o derivadas por un juez a resolver sus diferencias en un procedimiento de mediación con un mediador cualificado y fuera del proceso judicial. En caso de alcanzarse un acuerdo, éste se presentará ante el Juez que dirigió a las partes a la mediación para que homologue dicho acuerdo que tendrá también fuerza ejecutiva ante los Tribunales si se incumple.

Podemos por tanto deducir que la única diferencia entre ambos tipos de mediación es la forma de acceso a la misma. La mediación intrajudicial se produce una vez iniciado el procedimiento por invitación del juez a las partes para que intenten el procedimiento de mediación en los servicios que los Juzgados prestan por medio de convenios con diversas Instituciones (v.gr. Colegios de Abogados). La mediación en el ámbito civil se puede iniciar bien de forma previa al proceso (como ocurre cuando las partes acuden a un mediador o a un abogado que les aconseja la resolución de un conflicto en una mediación). También puede realizarse, una vez iniciado el proceso, tras la invitación del juez o propuesta de las partes, en cuyo caso cabría acordar la suspensión del procedimiento judicial en tanto las partes comunican el acuerdo que podrían haber adoptado o la reanudación del proceso judicial caso de no haber dado sus frutos la mediación.

Por parte del Consejo General del Poder Judicial (CGPJ) se ha aprobado una "Guía de buenas prácticas" que recoge los protocolos relativos a la mediación Civil, Familiar, Penal, Social y Contencioso-Administrativa. En su Exposición de Motivos recoge que la derivación a mediación "disminuirá considerablemente el número de procesos 
judiciales que requieran sentencia, lo que sin duda redundará en una mayor calidad en la tarea de juzgados y Tribunales".

A continuación se muestra una comparativa de las derivaciones realizadas por los Tribunales españoles a mediación, las efectuadas por las partes y las que finalizan con o sin acuerdo. A este respecto debe tenerse en cuenta que en la mediación intrajudicial los índices de éxito (esto es, los supuestos en los que el mediador logra que las parten alcancen un acuerdo) son más bajos que en la mediación extrajudicial. 


\section{GRÁFICO}

Mediación intrajudicial en el ámbito Civil (2012-2015)

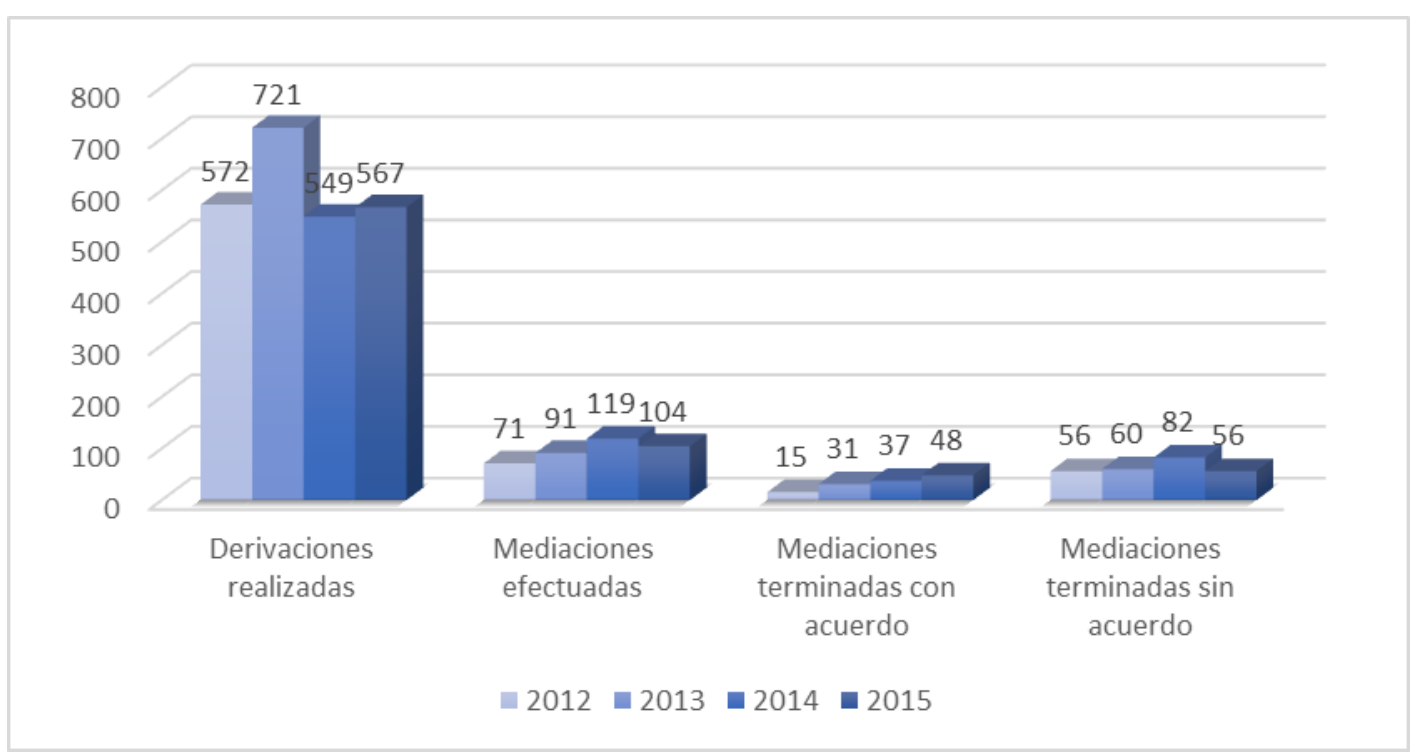

Fuente: Consejo General del Poder Judicial (2016)

\section{El pacto de sometimiento a la mediación. "Cláusula de mediación" o "Cláusula de mediación escalonada”.}

Con carácter general, se considera recomendable que la mediación sea un paso previo a cualquier otro procedimiento judicial o arbitral. De ahí, que resulte recomendable la inclusión de cláusulas de mediación ("mediation clauses”) en los contratos y en particular, de "cláusulas escalonadas" (también denominadas "multi-step dispute resolution clauses”). La incorporación de este tipo de cláusulas con ocasión de la suscripción del contrato por las partes implicaría que las partes se someterían a una mediación y caso de no solucionarse la controversia, dejaría abierta la posibilidad de acudir a los tribunales o al arbitraje ${ }^{8}$. La limitación temporal de la cláusula de mediación

\footnotetext{
${ }^{8}$ Este tipo de cláusulas es asimismo aplicable al ámbito societario, es decir, que puede recogerse en los estatutos sociales de una compañía y ser objeto de inscripción en el Registro Mercantil. A este respecto,
} 
conlleva que mientras se cumpla el intento de mediación o mientras este proceso se esté ejecutando, no se puede iniciar el procedimiento jurisdiccional o arbitral.

Se recoge a continuación una cláusula de mediación tipo propuesta para la redacción de cláusulas de Arbitraje Internacional publicado por la "International Bar Association" en 2010:

"Todas las controversias derivadas del presente contrato o que guarden relación con el mismo, incluyendo cualquier asunto relacionado con su existencia, validez o terminación ("Controversia"), serán resueltas de conformidad con los procedimientos especificados a continuación, los cuales serán los únicos y exclusivos procedimientos para la resolución de tal Controversia.

(A) Negociación. Las partes deberán esforzarse por resolver cualquier Controversia amigablemente mediante negociación entre las partes con autoridad 9 para resolver la Controversia.

(B) Mediación. Cualquier Controversia no resuelta mediante negociación de conformidad con el párrafo (A) dentro de los [30] días siguientes a que cualquiera de las partes haya solicitado por escrito la negociación establecida en el párrafo (A), o dentro de otro período que las partes acuerden por escrito, será resuelta amigablemente a través de mediación bajo el [reglamento de mediación seleccionado].

(C) Arbitraje. Cualquier Controversia que no haya sido resuelta por la mediación prevista en el párrafo $(B)$ dentro de los [45] días siguientes al nombramiento del mediador o dentro de otro período que las partes acuerden por escrito, serán resueltas definitivamente de acuerdo con [el reglamento de arbitraje seleccionado] por [uno o tres] árbitro[s] nombrados de conformidad con dicho reglamento. El lugar del arbitraje será [ciudad, país]. El idioma del arbitraje será [...]. [Todas las comunicaciones durante la negociación y mediación conforme a los párrafos (A) y (B)

cabe destacar la Resolución de la DGRN de 25 de junio de 2013 que declara la validez de la sumisión a mediación y a arbitraje de los conflictos que surjan entre administradores, tras la inscripción parcial realizada por el registrador mercantil de una cláusula de sumisión de toda controversia o conflicto de naturaleza societaria a mediación y a arbitraje, con la exclusión inicial de la expresión "entre los administradores".

9 Refiriéndose a representantes con capacidad para representar a las partes. En caso de una sociedad mercantil, será el legal representante, su administrador/es o personas debidamente apoderadas. 
serán confidenciales y se considerarán como efectuadas en el curso de negociaciones de transacción y avenimiento a los fines de las normas aplicables en materia probatoria y de confidencialidad y secreto profesional previstas en el derecho aplicable.]."

En relación con el contenido de la cláusula, las partes pueden concretar otras cuestiones además del sometimiento a la mediación, tales como prever una cláusula penal por incumplimiento de la misma (v.gr. pago de costas), limitar los asuntos mediables o incluir la regulación de aspectos procedimentales que no contradigan los principios de la institución. Debe tenerse en cuenta que durante el tiempo en que se desarrolle la mediación las partes no podrán ejercitar contra las otras partes ninguna acción judicial o extrajudicial en relación con su objeto, con excepción de la solicitud de las medidas cautelares u otras medidas urgentes imprescindibles para evitar la pérdida irreversible de bienes y derechos (art. 10.2. LM).

En cuanto a la eficacia del pacto, podemos entender que la buena fe en el cumplimiento de la cláusula exige por lo menos acudir a la sesión informativa prevista en el inicio del proceso de mediación (art. 17.1. LM). Si no se asiste injustificadamente existirá incumplimiento de la cláusula, lo que supondrá que se habrá desistido de la mediación.

La cláusula puede incumplirse de forma activa o pasiva:

- Se incumple de forma activa cuando una de las partes acude directamente a los tribunales obviando la cláusula de sometimiento a la mediación. Ello abriría a la parte interesada la posibilidad de invocar la cláusula mediante la interposición de la declinatoria. Recoge el art. 39 LEC que el demandado podrá denunciar la falta de jurisdicción mediante declinatoria.

- Se incumple de forma pasiva cuando una de las partes no asiste a la sesión informativa de forma injustificada, supuesto que la ley asimila al desistimiento de la mediación. Establece el art. 17.1 LM que "En caso se inasistencia injustificada de cualquiera de las partes a la sesión informativa se entenderá que desisten de la mediación solicitada". 


\subsection{La mediación voluntaria.}

Según se ha expuesto con anterioridad, la Ley 5/2012, de 6 de Julio, de Mediación asume un modelo de mediación basado en la voluntariedad. La barrera material de la mediación es que su contenido no afecte a "derechos y obligaciones" que no estén a disposición de las partes en virtud de la legislación aplicable (art. 2.1. LM). La condición voluntaria de la cláusula de mediación y la limitación temporal de ésta, podría dar lugar a maniobras dilatorias. No obstante, debe tenerse en cuenta que de acuerdo con lo dispuesto en el art. 4 LM la solicitud de inicio de la mediación suspende los plazos de caducidad y prescripción desde la fecha en que conste la solicitud o recepción de la solicitud (siempre que existiere un pacto previo o una cláusula de mediación).

A este respecto, la propia Ley de Mediación establece que "Nadie estará obligado a mantenerse en el procedimiento de mediación ni a concluir el acuerdo” (art. 6.3. LM). Asimismo se establece "Si en 15 días no se firma el acta constitutiva del proceso mediatorio, se reanuda el cómputo de los plazos y también se reanuda cuando se firma el acuerdo de mediación o el acta final, o cuando la terminación del procedimiento se produce por cualesquiera de las causas establecidas en el art. 22 de la Ley”.

La Ley procesal española impulsa de manera indirecta el sometimiento a mediación de determinados asuntos. En particular, con ocasión de la audiencia previa en los procedimientos de juicio ordinario, especifica la norma la obligación de informar a las partes sobre el posible recurso a la mediación. En concreto, el art. 464 de la Ley de Enjuiciamiento Civil (o "LEC") ${ }^{10}$ recoge que "En esta convocatoria, si no se hubiere realizado antes, se informará a las partes de la posibilidad de recurrir a una negociación para intentar solucionar el conflicto, incluido el recurso a una mediación, en cuyo caso éstas indicarán en la audiencia su decisión al respecto y las razones de la

\footnotetext{
${ }^{10} \mathrm{Si}$ bien el precepto legal hace referencia a la "negociación" y a la mediación, deben ser distinguidos ambos conceptos al tratarse de procesos distintos.
} 
misma”. Por su parte, el art. 415 LEC recoge la oportunidad de las partes de someter su conflicto a una mediación al prever "Las partes de común acuerdo podrán también solicitar la suspensión del proceso de conformidad con lo previsto en el artículo 19, para someterse a la mediación”.

Por otro lado, la Ley 14/2013, de apoyo a los emprendedores y su internacionalización, ha introducido una nueva figura, la del denominado "mediador concursal", que nace con dos objetivos. En primer lugar, es de obligada presencia ante la solicitud, por parte del interesado-deudor, de intentar un acuerdo extrajudicial de pagos y, en segundo lugar, se configura como mediador especializado en el marco de la Ley 5/2012, de 6 de julio, de mediación (LM) y como posible administrador concursal ante, en su caso, el nuevo instituto del concurso consecutivo del 242 de la Ley Concursal que en su segundo apartado recoge "Salvo justa causa, el juez designará administrador del concurso al mediador concursal en el auto de declaración de concurso".

\subsection{La mediación obligatoria.}

La mediación (antes conciliación) era obligatoria como presupuesto procesal hasta 1986 ya que en la Constitución de Cádiz se estableció que no se podía iniciar un proceso judicial sin acreditar haber intentado antes el citado proceso extrajudicial. En la Carta Magna de los Jueces, de 17 de Noviembre de 2010, se dispone también que los jueces tienen la obligación de "contribuir a la promoción de métodos alternativos de resolución de conflictos".

Actualmente, es pacífico entre la doctrina que la mediación tiene como base la autonomía de la voluntad de las partes, al igual que ocurre con el arbitraje ${ }^{11}$. Cabe por

\footnotetext{
11 Vid. CAZORLA GONZALEZ, M.J., "La mediación de consumo en el arbitraje institucional", International Workshop on ADR/ODRs, Universitat Oberta de Catalunya (UOC), 2009, p. 9. Afirma CAZORLA "entendemos, que la autonomía de la voluntad de las partes es el núcleo fundamental a la hora de resolver un conflicto bajo cualquiera de las diferentes alternativas de resolución extrajudicial de conflictos, sobre todo en aquellas donde la solución la aportan ellos".
} 
tanto sostener que con carácter general la mediación no es obligatoria ni en el ámbito civil ni en el mercantil. No obstante, si resulta obligatoria la conciliación en determinados asuntos, como ocurre con las conciliaciones laborales/sociales antes de interponer la correspondiente demanda ante el Juzgado de lo Social o en el ámbito penal, respecto de los delitos de injurias y calumnias.

En el ámbito social, recoge el art. 63 de la Ley reguladora de la Jurisdicción Social que "Será requisito previo para la tramitación del proceso el intento de conciliación o, en su caso, de mediación ante el servicio administrativo correspondiente o ante el órgano que asuma estas funciones [...]”. Por su parte, en el ámbito penal prevé el art. 804 de la Ley de Enjuiciamiento Criminal que "no se admitirá querella por injuria o calumnia inferidas a particulares si no se presente certificación de haber celebrado el querellante acto de conciliación con el querellado o haberlo intentado sin efecto".

Según se desprende del Informe de la Comisión Europea de fecha 26 de Septiembre de 2016, en relación con la aplicación de la Directiva 2008/52/CE del Parlamento Europeo y del Consejo sobre determinados aspectos de la mediación en el ámbito civil y mercantil, el modelo de mediación obligatoria (también conocido como "mandatory mediation") implantado en determinados países comunitarios ha mostrado resultados positivos. ${ }^{12}$ La asistencia a las sesiones de mediación se ha convertido en algunos países en una condición previa para el acceso al procedimiento judicial en determinados asuntos. Dicha obligación se establece en unos casos por iniciativa del juez (como ocurre en la República Checa) o en los asuntos previstos legalmente relativos a Derecho de familia (según está regulado en Lituania, Luxemburgo, Inglaterra y Gales). Italia ha ido más allá de lo previsto por la Directiva, estableciendo supuestos en los que la mediación es obligatoria, lo que habría ayudado a descongestionar los Tribunales.

Recoge dicho Informe en sus conclusiones que la Directiva no necesita ser revisada, si bien su aplicabilidad podría ser mejorada. En particular, propone que los países integrantes de la Unión Europea deberían incrementar sus esfuerzos para promover el

12 A este respecto es muy interesante el siguiente trabajo: HERRERA DE LAS HERAS, R.: "La Mediación Obligatoria para Determinados Asuntos Civiles y Mercantiles", en InDret, Vol. 1, 2017. 
uso de la mediación a través de distintos medios y mecanismos previstos en la Directiva (v.gr. incrementar los supuestos en los que los jueces tendrían que invitar a las partes a usar la mediación para solventar su conflicto y los casos en los que fuera obligatorio acudir a la sesión informativa u ofrecer incentivos, además de asegurar la ejecutividad de los acuerdos).

Cabe por tanto sostener que no se puede imponer a las partes que se sometan a un procedimiento de mediación, pero sí invitarlas al mismo o al menos que asistan a la sesión informativa con el objetivo de que valoren la posibilidad de acudir a dicho procedimiento $^{13}$. Según sostuvo el Consejo de Estado en su Informe sobre el Anteproyecto de Ley de Mediación para asuntos civiles y mercantiles, el hecho de que se imponga la mediación en determinados procesos judiciales "es compatible con el principio de voluntariedad que se proclama de la mediación". Y ello, debido a que según se ha expuesto, las partes son libres para continuar con el procedimiento y concluir, en su caso, un acuerdo.

Adicionalmente, debe tenerse en cuenta que de acuerdo con lo dispuesto en la citada Ley de Mediación (art. 3 LM), en los asuntos transfronterizos cuando las partes residan en distintos Estados Miembros de la Unión Europea, el domicilio se determinará conforme a lo dispuesto en el Reglamento (CE) núm. 44/2001 del Consejo, de 22 de diciembre de 2000, relativo a la competencia judicial, el reconocimiento y la ejecución de resoluciones judiciales en materia civil y mercantil. Por ello, aunque el legislador español se ha decantado por un modelo de mediación "voluntaria", no se puede obviar que el carácter transfronterizo de un conflicto puede conllevar que se acuda a una mediación "obligatoria”, todo ello en función de cuál sea la ley que resulte aplicable.

\footnotetext{
${ }^{13}$ SANTOR SALCEDO, H. "La conceptuación de la mediación en los acuerdos interprofesionales sobre solución de conflictos”, La Ley, 2009, p. 6. En palabras de la autora, la denominada «mediación intentada sin efecto» es aquella que tras ser solicitada por una parte se salda con la incomparecencia de la otra, no es, por ello, mediación, sino un intento de mediación frustrado por la falta de voluntad, presupuesto sine qua non para que el negocio se perfeccione. Y mal cabe hablar de obligatoriedad de la medición si, realmente, no existe mediación sino su intento.
} 
5. Conclusiones.

Cuando se trata de solucionar controversias y en especial en el ámbito empresarial, en España solemos acudir al procedimiento judicial y en estos últimos años al arbitraje. Sin embargo debe tenerse en cuenta que existe otro medio para solucionar las disputas cuyo uso está poco expandido en nuestro país, denominado mediación. Dicho proceso presenta numerosas bondades, incluido el ahorro de tiempo, de costes y la no ruptura de las relaciones contractuales en términos de salvar la continuidad de la relación contractual o comercial.

Según se desprende de lo anteriormente expuesto, el procedimiento de mediación puede iniciarse de común acuerdo entre las partes, pero también por una de las partes en cumplimiento de un pacto de sometimiento a mediación existente entre ellas. La validez de las cláusulas de sumisión a mediación es perfectamente compatible con el carácter voluntario de la mediación, ya que las primeras son consecuencia del ejercicio por las partes del principio de autonomía de voluntad (art. 1255 Cód. Civ.).

La admisibilidad de estas cláusulas queda condicionada a que hayan sido efectivamente queridas por las partes y que por el contrario, no hayan resultado de la imposición de una de ellas. Dicho pacto, deberá ser expreso y se deberá intentar el procedimiento pactado de buena fe antes de acudir a la jurisdicción o cualquier otra solución extrajudicial. Sin embargo, cuando las partes hayan pactado la mediación sí cabe dejar sin efecto tal pacto de forma expresa o de forma tácita. Se entenderá que existe un desistimiento tácito caso de no haber interpuesto la declinatoria al iniciarse el procedimiento por otra vía distinta a la de la mediación (art. 56.2 LEC). Caso de omitirse el intento de mediación a través de una convocatoria para asistir a una primera sesión del proceso y acudir a la vía judicial podría interponerse una declinatoria (art. 63.1 LEC) por falta de jurisdicción de los tribunales.

Cabe añadir que el incumplimiento de lo pactado en esta materia, está desprovisto actualmente de sanción. A este respecto debe tenerse en cuenta que las partes no pueden 
imponer la comparecencia del acto de mediación de la parte no solicitante. Por tanto, puede entenderse que existe obligación de convocar a las partes a instancia de una de ellas, pero no cabe hablar de obligatoriedad del proceso de mediación.

En conclusión, resulta recomendable en las relaciones contractuales y en especial en las relaciones comerciales, fomentar la inclusión de cláusulas de mediación escalonadas que prevean el compromiso de las partes de someter la controversia a negociación, caso de no prosperar la misma, a mediación y en caso de no encontrarse una solución, al arbitraje. A este respecto, resultaría de utilidad que la voluntad conciliadora se muestre también por las Administraciones Públicas cuando la materia sea disponible y la ley lo permita, impulsando que determinadas situaciones sean resueltas bajo el paraguas de la mediación según se promueve desde las instituciones comunitarias. No obstante, sólo el tiempo nos dirá si se ha conseguido fomentar la cultura emprendedora de la mediación en nuestro país. 


\section{REFERENCIAS BIBLIOGRÁFICAS:}

ÁLVAREZ SACRISTÁN, I., "La Mediación Civil y Mercantil (Comentarios y formularios)", Gomylex, Bilbao, 2012.

BAIXAULI, E., "El conflicto empresarial: una guía para ofrecer soluciones", Tirant lo Blanch, 2010.

BARONA VILAR, S., "Solución extrajurisdiccional de conflictos/Alternative Dispute Resolution (ADR) y Derecho Procesal”, Tirant lo Blanch, Valencia, 1999.

BERCOVITZ RODRÍGUEZ-CANO, R., “Obligaciones y Contratos”, Cuadernos Civitas de Jurisprudencia Civil, Thomson Reuters, 2009.

BONET NAVARRO, Á., "Proceso Civil y Mediación. Su análisis en la Ley 5/2012, de Mediación en asuntos civiles y mercantiles”, Thomson Reuters, Pamplona, 2013.

BUTTS GRIGGS, T., "La mediación en los Estados Unidos: contexto y experiencias". Cuadernos de Derecho Judicial, núm. V, Consejo General del Poder Judicial, 2005.

CARRASCO PERERA, Á. y otros, “Derecho de Contratos”, Aranzadi, 2010.

CASTILLA BAREA, M., "La imposibilidad de cumplir los contratos", Dykinson, 2000.

CAZORLA GONZALEZ, M.J., "La mediación de consumo en el arbitraje institucional", International Workshop on ADR/ODRs, Universitat Oberta de Catalunya (UOC), 2009. 
CGPJ (Consejo General del Poder Judicial), "Guía para la práctica de la mediación intrajudicial", CGPJ, Madrid, 1990.

CGPJ, "Cuadernos de Derecho Judicial. Arbitraje, Mediación, Conciliación”, CGPJ, Madrid, 1995.

CLIFFORD J. H., "La mediación empresarial: una inversión indiscutible", La Ley, 2013.

FISHER R., URY W. y PATTON, B., "Sí de Acuerdo! Cómo negociar sin ceder”, Ed. Norma SA, Colombia, 1991.

GINEBRA MOLINS, M. y otros, "La obligatoriedad de la mediación derivada de la voluntad de las partes: la cláusula de mediación”, InDret, Octubre 2013.

HUALDE MANSA, T., "La Mediación en asuntos civiles y mercantiles. La transposición de la Directiva 2008/52 en Francia y en España”, La Ley, 2013.

LAUROBA, E. y cols., "Materiales jurídicos del Libro Blanco de la Mediación en Cataluña", Generalitat de Catalunya, Centre d'Estudis Jurídics i Formació Especialitzada, 2011.

LÓPEZ SIMÓ, F. y otros, "Mediación en materia civil y mercantil. Análisis de la normativa de la UE y española”, Tirant lo Blanch, Valencia, 2014.

GARCÍA ÁLVAREZ, R., "La Mediación en asuntos civiles y mercantiles: guía para abogados", Diario la Ley, núm 7828, Marzo de 2012.

GARCÍA ÁlVAREZ, R., “Guía de mediación para abogados”, Diario la Ley, Núm. 7828, Marzo de 2012. 
GONZÁLEZ PILLADO, E. (Coord.), “Arbitraje y mediación en materia de consumo”,

Tecnos, Madrid, 2012.

GUTIÉRREZ SANZ, Ma R., "La cuestión declinatoria en el Real Decreto- Ley 5/2012, de 5 de marzo, de Mediación en asuntos civiles y mercantiles", Diario la Ley, Núm. 7871, Sección Tribuna, Junio de 2012.

HEREDIA CERVANTES, I., "Medios alternativos de solución de controversias", Universidad Autónoma, Madrid, 2009.

HINOJOSA SEGOVIA, R. (Coord.), "Sistemas de Solución extrajurisdiccional de conflictos", Madrid, 2006.

LORCA NAVARRETE, A. Ma, "La Mediación en asuntos civiles y mercantiles. Real Decreto-ley 6/2012, de 5 de marzo", Instituto Vasco de Derecho Procesal, San Sebastián, 2012.

MARQUÉS CEBOLA, C., “La Mediación”, Marcial Pons, 2013.

MOORE, C., "El proceso de Mediación. Métodos prácticos para la resolución de conflictos", Granica, 1995.

MUNDUATE, L. y otros, "Manual para la Mediación Laboral", en web www.mediacion.icav.es/archivos/contenido/273.pdf [Consulta: 15 de Octubre de 2016].

NAVARRO, M., "Real Decreto-Ley 5/2012, de 5 de marzo, de Mediación en asuntos civiles y mercantiles: un nuevo horizonte para la solución pactada de controversias privadas”, Diario La Ley, Núm. 7866, Mayo de 2012.

OLIVENCIA RUIZ, M., “Arbitraje: una justicia alternativa”, Universidad de Córdoba, Córdoba, 2006. 
ORTUÑO MUÑOZ, J. y otros, "Sistemas alternativos a la resolución de conflictos (ADR): las mediación en las jurisdicciones civil y penal", Documento de trabajo 110/2007, Fundación Alternativas, 2007.

PALAO MORENO, G., "Autonomía de la voluntad y mediación en conflictos transfronterizo en el Real Decreto-Ley 5/2012”, Diario la Ley, Núm. 7847, Abril de 2012.

PÉREZ GURREA, R., “La Mediación como método de resolución extrajudicial de conflictos: su regulación y efectos en el Real Decreto-Ley 5/2012, de 5 de marzo”, Diario La Ley, Núm. 7878, Junio de 2012.

PÉREZ MORIONES, A., "La sumisión de los conflictos entre administradores a mediación y a arbitraje (RDGRN de 25 de junio), Diario La Ley, Octubre de 2013.

PEREZ MORIONES, Aránzazu, "En torno a la paradoja de la Mediación”, Diario la Ley, Núm. 8316, Mayo de 2014.

PRATS ALBENTOSA, Lorenzo, "La nueva regulación europea de la mediación”, El Diario la Ley, núm. 6958, Junio 2008.

SANTOS BRIZ, J. (Dr.), “Tratado de Derecho Civil”, Bosch, Barcelona, 2003.

SANTOR SALCEDO, H. "La conceptuación de la mediación en los acuerdos interprofesionales sobre solución de conflictos", La Ley, 2009.

SOLETO, H. y cols., "Mediación y resolución de conflictos: técnicas y ámbitos", Tecnos, 2011.

SOSPEDRA NAVAS, F., "Medición y Arbitraje. Los sistemas alternativos de resolución de conflictos”, Thomson Reuters, Pamplona, 2013. 
TRIGO SIERRA, E. y otros, "La Mediación Civil y Mercantil en España y en el Derecho Comparado, Actualidad Jurídica Uría Menéndez, Núm. 32, 2012.

VÁZQUEZ DE CASTRO, E., "Practicum Mediación”, Thomson Reuters, Pamplona, 2013.

ZAERA NAVARRETE, J. y otros, "Guía Práctica de Mediación. 100 preguntas y respuestas para abogados”, Tirant lo Blanch, Valencia, 2013. 